\title{
Accommodating High PV Penetration on the Distribution System of Kinmen Island
}

\author{
Yuan-Kang $\mathrm{Wu}^{1}$, Shao-Hong Tsai ${ }^{2}$, Ming-Yan Zou ${ }^{1}$ \\ ${ }^{1}$ Department of Electrical Engineering, National Chung-Cheng University \\ ${ }^{2}$ Department of Electrical Engineering, Hwa Hsia Institute of Technology \\ Email: allenwu@ccu.edu.tw, shtsai@cc.hwh.edu.tw
}

Received February, 2013

\begin{abstract}
A large-scale PV installation has a profound effect on the power quality and operation of the grid. Therefore, as installations of PV systems increase, changes to both technologies and interconnection standards are needed to address these high PV penetration systems. This paper investigates the main technical impacts of large-scale PV generations on power grids and associated interconnection standards. A case study by using the PSS/E software in the Kinmen power system was implemented to study the steady-state and transient characteristics for the high penetration PV systems.
\end{abstract}

Keywords: PV; Penetration; Interconnection Standard; PSS/E; Kinmen

\section{Introduction}

There is an increasing introduction of renewable energy generation into power grids, like wind power and photovoltaic (PV) generations, which causes control and operation problems to the utilities since the networks have not been pre-designed to take into account these distributed or intermittent generations. The electricity from PV is difficult to predict and mainly dependent on weather conditions. Furthermore, they are usually connected to grid through power electronic converter, and this also presents a significant difference from conventional generators. As the penetration of the solar PV plant increases, its impact on the stability and operation of the grid needs to be well understood. Because of the intermittency of the output from solar plants, these impacts might be significant, especially when the solar irradiance drops from $100 \%$ to $20 \%$ in a minute, causing numerous problems in a high penetration scenario. Additionally, since traditional feeders are commonly designed for radial unidirectional power flows, it is expected that some of the most significant impacts occur for large PV penetration levels.

The main technical impacts of large scale PV generations on power grid are: voltage, current profiles, power quality, protection, electric losses, power factor, power balancing, reliability, protection and operability of the system. Solar PV generation impacts can be of steady state or dynamic in nature. These impacts vary in severity as a function of the degree of penetration and location of solar PV distributed generation. For instance, PV generation is generally at its optimal around moon, and gen- erally this is a period of light load condition; therefore, power export through the distribution feeder and the substation back to the system becomes possible. The associated reverse power flow will tend to raise the voltage on the distribution feeder. Additionally, introducing PV at the load side would reduce the load demand and in turn leads to reduced losses and improved voltage profiles on the feeder. This is an important benefit from a capacity planning perspective since it allows utilities to defer capital investments.

Typical system integration problems in large PV systems include [1]: no dispatch capability of PV solar farms without storage, ultra-fast ramping requirements (400 - $1000 \mathrm{MW} / \mathrm{min})$, reactive power management of feeders are not designed with high PV production, power quality, especially voltage fluctuations, flicker and harmonics may be out of IEEE-519 and other standards. Several research works [2] indicate that the impact is lower in the case of distributed PVs compared to concentrated PVs with the same penetration level, and a larger grid with slow-response generators experiences larger variations in system.

In the USA, the department of energy (DOE) solar energy conducted a competitive Funding Opportunity Announcement, and six competitively selected projects have been completed [3]. For example, several projects used actual distribution feeders as the basis for model development and testing high PV penetration; according to the research results, PV inverter capabilities may be useful in mitigating system impacts. Intelligent inverters are expected to provide significant benefit to future elec- 
tric distribution system operations. As PV penetration rises, new functionality from the inverter would need to be incorporated. Advanced PV inverters should have the following features: reactive power control, low voltage ride through, dynamic control, and works like a traditional synchronous generator.

Some of the projects demonstrated how the high penetration of PV will affect operations of an electric distribution grid. Other important research items in these DOE projects include the evaluation of the effects of energy storage in combination with distributed PV generation, the benefits from high resolution data collection, the impact of PV system integration on power system reliability indices, the impact of cloud movement on power quality, the impact of feeder configuration and the PV location on the maximum PV penetration.

This paper investigates several potential problems associated with high penetration levels of grid-tied PV. Additionally, interconnection codes or standards for PV generation and major requirements will be studied. Finally, a case study by using the PSS/E software in the Kinmen power system was implemented to study the steady-state and transient characteristics for the high penetration PV systems.

\section{Potential Problems Associated with High Penetration Levels of Grid-tied PV}

The International Energy Agency (IEA) has produced a series of reports on Task $\mathrm{V}$ of the PV power systems (PVPS). The demonstration projects issued by the IEA have revealed that voltage rise is one of the primary concerned problems [4]. The study in [5] also indicates that PV penetration is limited to approximately $33 \%$ by voltage rise issues in the UK. A study from Japan [6] suggested that voltage rise is the most serious problem and would limit penetration levels between 5\% and 20\%. Any injection of power into a distribution system would cause a voltage rise at the point of connection, and this must be considered by network operators.

Voltage dips due to cloud transients might be an issue at high PV penetration. Cloud cover and morning fog require fast ramping and power balancing. Several research works [7] examined cloud transient effects if the PV were deployed as a central-station plant, and the results indicate that the maximum tolerable system level penetration level of PV would be limited by the transient following capabilities (ramp rates) of the conventional generators. Additionally, slow voltage regulation and fast voltage regulation in high penetration $\mathrm{PV}$ scenarios should also be addressed. To mitigate the effects of PV output variability, energy storage systems are another option, in which the PV inverter control system is integrated into the system. The storage system will generate or absorb energy as the PV power fluctuates according to the available solar resource.

In terms of power quality, the results of several research works reveal that the PV contribution to voltage distortion is far less than the contributions made by many customer loads [8]. Therefore, harmonics would not be a problem as long as the inverter has a well design.

\section{Interconnection Codes and Standards}

Grid connection guidelines are a major subject with regard to PV generation. The connection rules and technical requirements that differ from region to region make it more complicated. IEC has been developing many standards related to individual DG technologies including PV generators. These guidelines would serve as input to develop a more general connecting guideline for all types of distributed generation systems and their interactions with the grid. In 2000, the IEEE published IEEE Standard 929 IEEE Recommended Practice for Utility Interface of Photovoltaic (PV) Systems up to $10 \mathrm{~kW}$ [9]. This standard was updated from IEEE Standard 929-1988 by incorporating developments in the PV industry and by coordinating with UL1741 1999; meanwhile, the IEEE Standards Coordinating Committee 21 on Fuels, Photovoltaics, Dispersed Generation, and Energy Storage formed a working group to develop the IEEE Standard for Interconnecting Distributed Resources with Electric Power Systems, or IEEE Standard 1547 [10]. It provides a uniform standard for interconnection of distributed resources with electric power systems, and also provides requirements relevant to performance, operation, testing, safety and maintenance of the interconnection. In Europe, every country has its own technical requirements. However, major requirements in these interconnection codes for distributed generators or PV generation include general requirements and specifications, safety and protection requirements, and power quality requirements.

For general requirements and specifications, most standards use a power size to limit the scope. IEEE 929 uses $10 \mathrm{~kW}$ and limits the technology to PV systems, while IEEE 1547 uses 10 MVA and attempts to cover all technologies. In addition, different PV interconnection standards specify different requirements on voltage variation, system frequency, synchronization, and voltage unbalance. As for safety and protection requirements, PV generators must detect and respond to abnormal conditions occurring on the power distribution systems. For instance, in almost all technical requirements and standards, unexpected islanding operation is not wanted. PV units must be disconnected as soon as possible when the main grid is not energized. All interconnected PV plants must have a readily accessible, lockable, visible-break isolation switch shall be located between the DG unit and the grid. This disconnection switch must accessible to the distribution company. In addition, after grid fault, the 
reconnection of the DG should be automatic once the grid voltage and frequency have returned to and maintained normal ranges.

PV generators should provide electric power to the grid with acceptable power quality. Generally, the requirements of interconnection standards include the limits on harmonic, DC current injection, flicker, and power factor. PV units using power electronic converters may inject harmonic currents in the network. The level of harmonics produced by the PV should not cause any disturbances on the distribution system. Many interconnection codes require specific values for different order harmonics and the total harmonic distortion. Flicker can be the result of fast variations of power output of generators or rapid changes in load current like arc furnaces or induction motor starting leading to significant voltage changes on the feeder. In order to reduce or avoid flicker, many countries require the maximum installed power is several times smaller than the level of the short-circuit capacity at the power common coupling (PCC) point. The PV unit shall not create objectionable or observable flicker for other customers on the power system. DC injection is a problem because the increased DC voltage has the potential to increase saturation of magnetic components, such as cores of distribution transformers. This saturation, in turn, causes increased power system distortion. Following IEEE 1547, DC currents injected by DG must be smaller than $0.5 \%$ of its rated current at the connection point.

\section{Dynamic Model of PV Arrays}

\subsection{Modeling of PV Arrays}

The physics based relationship between the output current and voltage of the PV cell is given as [11]:

$$
I=I_{p h}-I_{O}\left(e^{\frac{q\left(V+R_{s} I\right)}{n K T}}-1\right)-\frac{V+R_{s} I}{R_{s h}}
$$

where, $I$ is output current from the cell, $V$ is output voltage of the cell, $I_{p h}$ is the generated current from photovoltaic action, Io is the reverse saturation current, $q$ is the charge of an electron, $k$ is Boltzmann's constant, $T$ is the ambient temperature and $n$ is the ideality factor.

\subsection{Dynamic PV Model in PSS/E}

The PV model was built using the user defined model integration feature of PSS/E. The PSS/E Solar PV Unit dynamic stability model was developed to simulate performance of a photovoltaic (PV) plant connected to the grid via a power converter. The model is based on the generic type 4 wind model, with the added ability to simulate output changes due to solar irradiation. The PV Generic Model comprises the following modules: power converter/generator module, electrical control module, linear model of a panel's output curve, and linear solar irradiance profile.

\section{Case Study}

The Kinmen power system (Figure 1) is chosen as the test system to integrate PV plants in PSS/E. Before adding any PV plants to the system, the load flow and dynamic study have been conducted in this work. Then, a few case studies were performed where PV plants are integrated at different buses (1101, 1104 and 1105) and the effect of the changes in solar irradiation and loss of PV plants for various penetration levels was observed.

\subsection{Effect of Sudden Change of Solar Irradiance on System Stability}

PV power is characterized as an intermittent source of energy as it is largely dependent on the environmental conditions. The solar irradiance can have 70 80\% drop in a minute. The drop out of a large PV power in such a short time could have significant impact on the system.

To investigate the impact on the system due to sharp changes in the level of radiation, the solar irradiance has been reduced from $1000 \mathrm{~W} / \mathrm{m}^{2}$ to $0 \mathrm{~W} / \mathrm{m}^{2}$ using different ramping down rate. The objective is to find out the critical rate beyond which the system might become unstable or require some load shedding action. Figure 2 shows the rate at which output power was changed due to the drop in solar irradiance at different rate, where PV penetration is $30 \%$. While the change in power for $\mathrm{PV}$ is shown in Figure 2, the change in the system frequency is shown in Figure 3. In this work, various scenarios with different ramping down rates on radiation and PV penetration have been simulated and the results are shown in Table 1. It was found that in $30 \% \mathrm{PV}$ penetration, the frequency of the PV connected bus for the case of solar

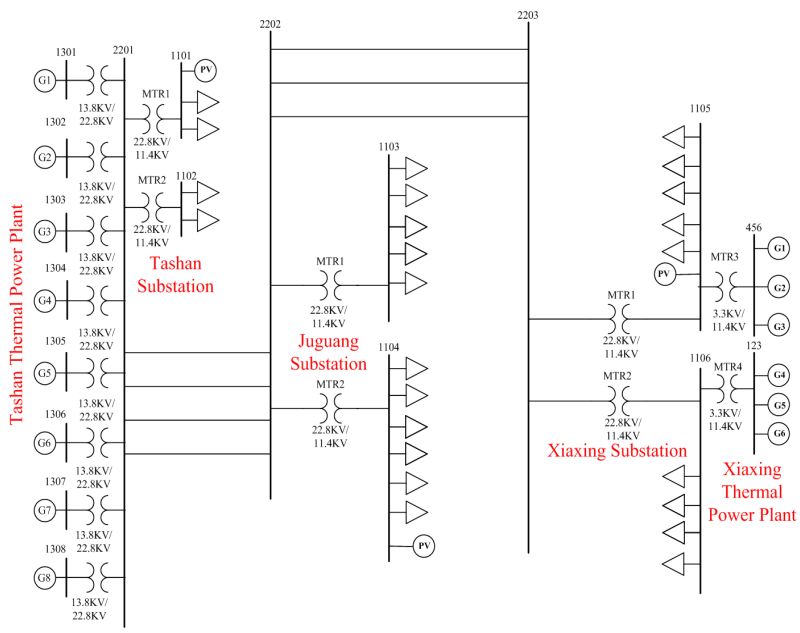

Figure 1. One-line diagram of the Kinmen power system. 


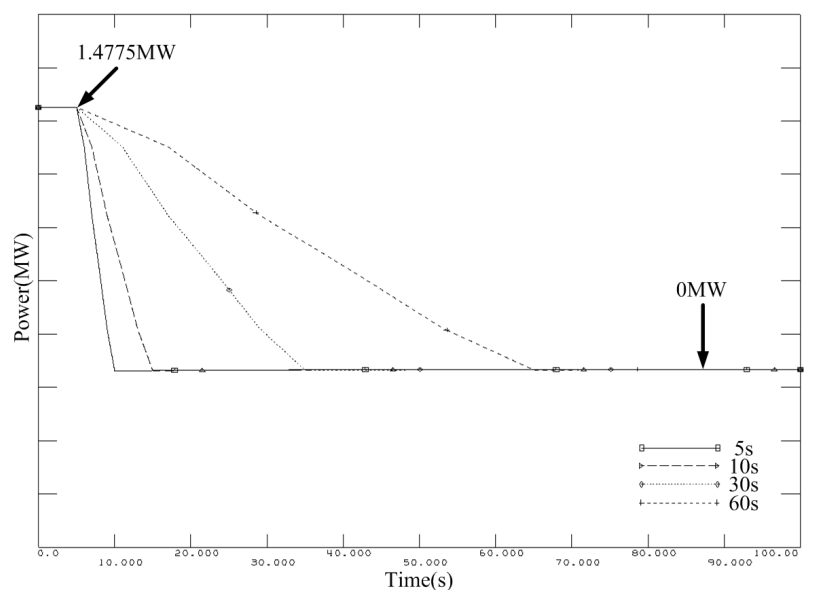

Figure 2. PV output power with $30 \% \mathrm{PV}$ penetration under different ramping down rate.

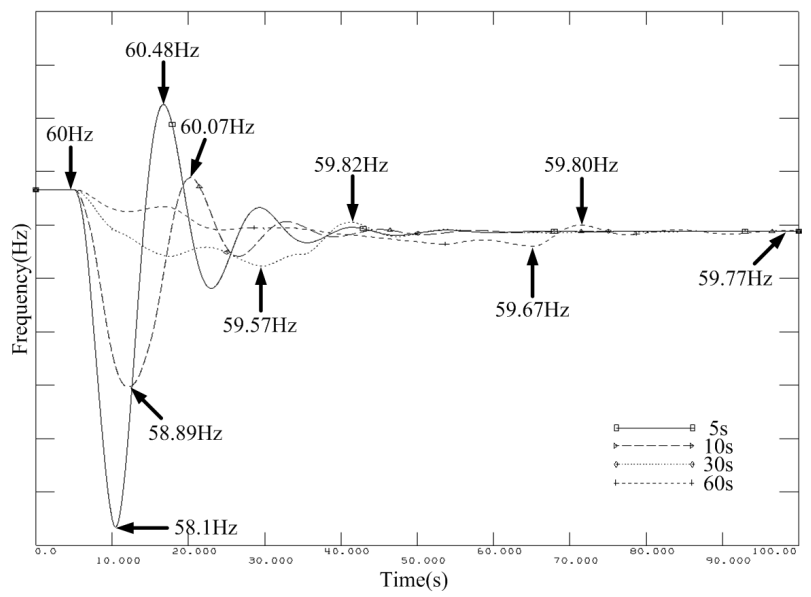

Figure 3. Frequency response with $30 \% \mathrm{PV}$ penetration in the Kinmen system.

Table 1. Frequency response under various scenarios.

\begin{tabular}{ccccc}
\hline Penetration & $5 \mathrm{~s}$ & $10 \mathrm{~s}$ & $30 \mathrm{~s}$ & $60 \mathrm{~s}$ \\
\hline $\mathbf{5 \%}$ & $59.68 \mathrm{~Hz}$ & $59.81 \mathrm{~Hz}$ & $59.93 \mathrm{~Hz}$ & $59.95 \mathrm{~Hz}$ \\
$\mathbf{1 0 \%}$ & $59.35 \mathrm{~Hz}$ & $59.62 \mathrm{~Hz}$ & $59.85 \mathrm{~Hz}$ & $59.89 \mathrm{~Hz}$ \\
$\mathbf{2 0 \%}$ & $58.73 \mathrm{~Hz}$ & $59.26 \mathrm{~Hz}$ & $59.71 \mathrm{~Hz}$ & $59.79 \mathrm{~Hz}$ \\
$\mathbf{3 0 \%}$ & $58.10 \mathrm{~Hz}$ & $58.89 \mathrm{~Hz}$ & $59.57 \mathrm{~Hz}$ & $59.68 \mathrm{~Hz}$ \\
\hline
\end{tabular}

irradiation change (from $1000 \mathrm{~W} / \mathrm{m}^{2}$ to $0 \mathrm{~W} / \mathrm{m}^{2}$ ) in $5 \mathrm{~s}$ drops to $58.1 \mathrm{~Hz}$ which is above the limit for a low-frequency load-shedding relay in the Kinmen power system to operate. If the PV penetration is continuously increased, we can find the critical PV penetration at which the frequency response indicated that the load-frequency load-shedding relay started to operate. The critical PV penetration in this study case under the solar irradiance drop of $1000 \mathrm{~W} / \mathrm{m}^{2}$ in $5 \mathrm{~s}$ is $42.5 \%$.

\subsection{Effect of Tripping all of PV Generation}

In this case, the expected worst case scenarios are demonstrated by assuming PV generator tripping. The PV penetration under $5 \%, 10 \%, 20 \%$ and $30 \%$ is simulated respectively. It is assumed that all of the PV generation are tripped out at time $t=2 \mathrm{~s}$. Figure 4 and Figure 5, show the system frequency and the voltage at bus 2201 respectively when all of the PV generators are tripped. From Figures 4 and 5, it can be observed that penetration level of PV power has significant impact on the system frequency and voltage. With the increase of penetration level, the severity of impact on system stability also increases. A trip of the PV generation creates momentary oscillations in the frequency. In Figure 4, the magnitude of the frequency perturbation is influenced by the penetration level. The higher the penetration, the higher is the magnitude of oscillation. For instance, for $30 \%$ penetration level, the system frequency goes down to $57.63 \mathrm{~Hz}$.

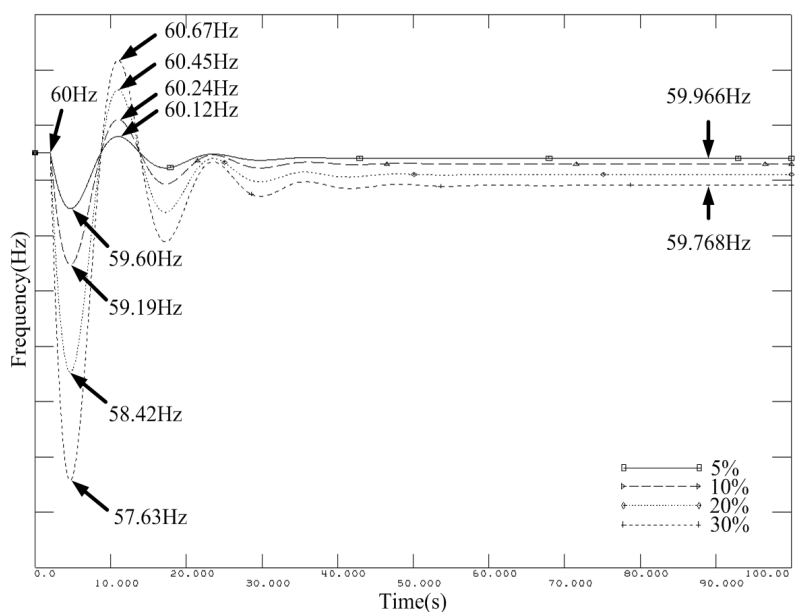

Figure 4. Frequency response in the Kinmen system if PV generation trips offline.

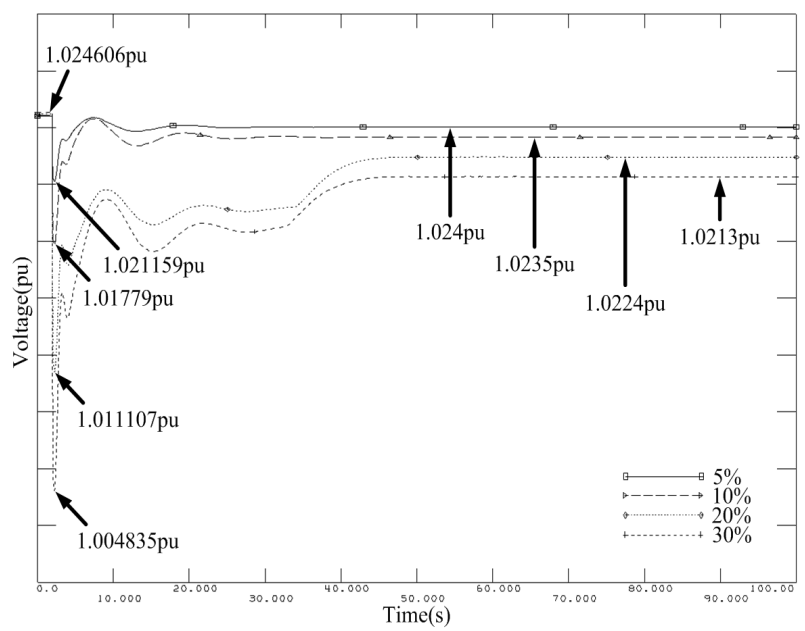

Figure 5. Transient voltage at bus 2201 in the Kinmen system if PV generation trips offline. 
If the PV penetration is continuously increased, we can find the critical PV penetration at which the frequency response indicated that the load-frequency load-shedding relay started to operate. The critical PV penetration in this study case (all of PV trip offline) is 34\%.

\subsection{Effect of a Three-phase Short Circuit Fault}

Another worst case scenario, a three phase short circuit fault, is applied at bus 2201 where the PV plant is connected. The fault was applied through very small impedance and lasted for $0.2 \mathrm{~s}$. The solar irradiance is assumed to remain constant at $1000 \mathrm{~W} / \mathrm{m}^{2}$ and therefore, the output power from the PV plant was at its maximum.

Due to the fault, the voltage at bus 2203 goes down to $0.058 \mathrm{pu}$ until the fault is cleared. As shown in Figure 6, when the fault was cleared, the voltage curve shows some transient with a maximum to a value of 1.11 p.u. volt. However, the oscillation damped down shortly and goes back to a normal value. Figure 7 shows the system

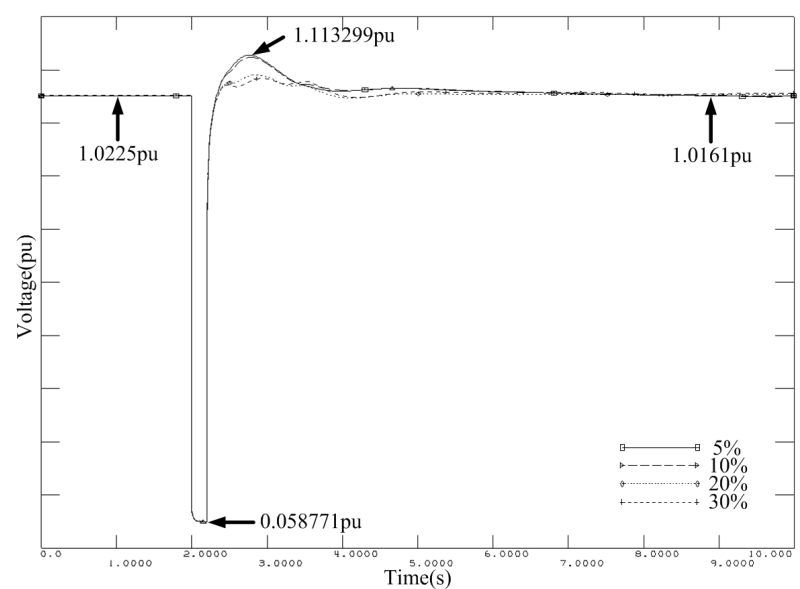

Figure 6. Voltage response in the Kinmen system if a threephase short circuit fault appears.

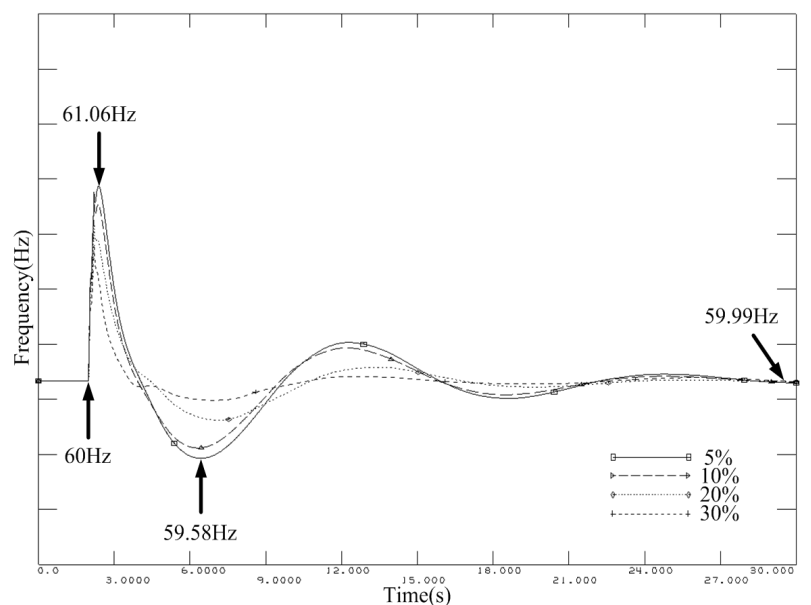

Figure 7. Frequency response in the Kinmen system if a three-phase short circuit fault appears. frequency response. The frequency shows oscillation and varies between $61.06 \mathrm{~Hz}$ and $59.58 \mathrm{~Hz}$ under 5\% penetration, which does not trigger a series of loads shedding relays. If the PV penetration increases, the oscillation amplitude reduces.

\subsection{Effect of PV on Steady-state Voltage and System Loss}

Load current flowing through line impedances and distribution transformers causes voltage drops along the feeder. Introducing distributed PV reduces the current being drawn from the substation and improves the voltage drop. The performance of grid at the point of connection for PV generators is an important factor for increasing the PV penetration. In this work, two types of PV generation configurations, i.e., concentrated and distributed, are considered in the simulation studies. For the concentrated configuration, all of the PV generators are installed on bus 1101. For the distributed configuration, PV plants are integrated at different buses (1101, 1104 and 1105). Figure 8 shows the simulation results for the voltage on bus 1101. It is found from Figure 8 that when the PV penetration increases, then the voltage on bus 1101 increases. Furthermore, the type of concentrated PV generation would cause larger voltage rise.

This work also investigates the system losses under different PV configurations. According to the simulation results, as $20 \%$ and $30 \%$ penetration is discussed, the

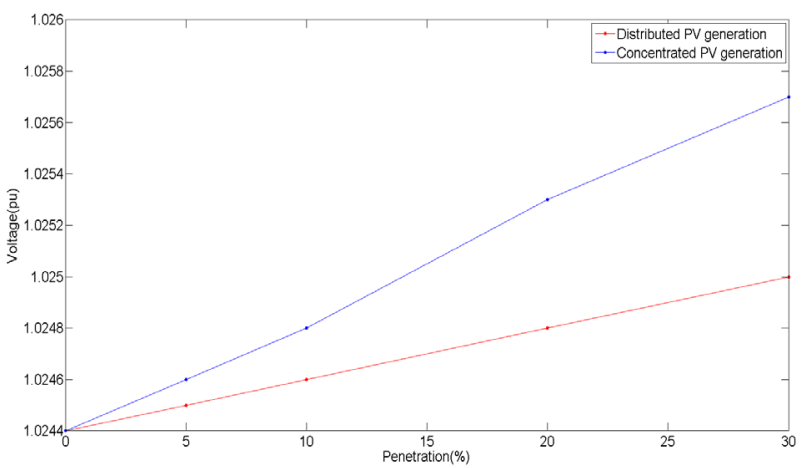

Figure 8. Voltage characteristic under different PV penetration and two types of PV generation configurations.

Table 2. System loss under different PV penetration and configurations.

\begin{tabular}{ccc}
\hline $\begin{array}{c}\text { Penetration } \\
(\%)\end{array}$ & $\begin{array}{c}\text { Distributed Type } \\
\text { (MW) }\end{array}$ & $\begin{array}{c}\text { Concentrated Type } \\
\text { (MW) }\end{array}$ \\
\hline 5 & 0.04 & 0.04 \\
10 & 0.04 & 0.04 \\
20 & 0.03 & 0.04 \\
30 & 0.03 & 0.04 \\
\hline
\end{tabular}


system power loss with distributed configuration type is lower than that with concentrated one. Additionally, the system power loss is reduced when the PV penetration is increased under the distributed configuration. As shown in Table 2.

\section{Conclusions}

As the integration of large and commercial scale PV on the distribution level, such systems can have considerable effect on the operation and protection of the system. This work investigates the main technical impacts of large scale PV generations on power grids and associated interconnection standards. Additionally, a case study by using the PSS/E software in the Kinmen power system was implemented to study the steady-state and transient characteristics for the high penetration PV systems. From the simulation results, several system disturbances, such as change of solar irradiance, tripping of PV generation, and three-phase short circuit fault would affect the maximum PV penetration as a grid. Moreover, PV generation penetration and configuration types would affect system voltage and power losses.

\section{Acknowledgements}

The authors gratefully acknowledge the financial support by Bureau of Energy, Ministry of Economic Affairs, R.O.C. under the Project "Development of Key Control Technologies for Distributed Energy System", and the National Science Council, Department of Executive, R.O.C. under the grant no. NSC-101-2221-E-146-009.

\section{REFERENCES}

[1] J. H. R. Enslin and P. J. M. Heskes, "Harmonic Interaction between a Large Number of Distributed Power Inverters and the Distribution Network," IEEE Transactions on Power Electronics, Vol. 19, No. 6, 2004, pp. 1586-1593.

\section{doi:10.1109/TPEL.2004.836615}

[2] S. A. Pourmousavi, A. S. Cifala and M. H. Nehrir, "Impact of High Penetration of PV Generation on Frequency and Voltage in a Distribution Feeder," North American Power Symposium, 2012.

[3] H. Thomas, K. Lynn and A. Razon, "Current Results of the US DOE High Penetration Solar Deployment Project," 38th IEEE Photovoltaic Specialists Conference (PVSC), 2012, pp. 731-736.

[4] A. Povlsen, "International Energy Agency Report," IEA PVPS T5-10: 2002, February; 2002. Available online at www.iea.org.

[5] M. Thomson and D. Infield, "Impact of Widespread Photovoltaics Generation on Distribution Systems," IET Journal of Renewable Power Generation, 007;1 (March (1)):33-40.

[6] H. Kobayashi and M. Takasaki, "Demonstration Study of Autonomous Demand Area Power System," IEEE PES Transmission and Distribution Conference and Exhibition, 2006, pp. 548-555.

[7] R. F. Yan and T. K. Saha, "Investigation of Voltage Stability for Residential Customers Due to High Photovoltaic Penetrations," IEEE Transactions on Power Systems, Vol. 27, No. 2, 2012, pp. 651-662.

[8] I. T. Papaioannou, M. C. Alexiadis, C. S. Demoulias, D. P. Labridis and P. S. Dokopoulos, "Modeling and Field Measurements of Photovoltaic Units Connected to LV Grid. Study of Penetration Scenarios,” IEEE Transactions on Power Delivery, Vol. 26, No. 2, 2011, pp. 979-987. doi:10.1109/TPWRD.2010.2095888

[9] IEEE, Standard 929-2000 IEEE Recommended Practice for Utility Interface of Photovoltaic (PV) Systems, 2000.

[10] IEEE, Standard 1547, Standard for Interconnecting Distributed Resources with Electric Power Systems, June 2003.

[11] M. G. Villalva, J. R. Gazoli and E. R. Filho,” Comprehensive Approach to Modeling andSimulation of Photovoltaic Arrays," IEEE Transactions on Power Electronics, Vol. 24, No. 5, 2009, pp. 1198-1208. doi:10.1109/TPEL.2009.2013862 